Physiol Behav. 2014 September ; 136: 121-127. doi:10.1016/j.physbeh.2014.04.025.

\title{
A functional neuroimaging review of obesity, appetitive hormones and ingestive behavior
}

\author{
Kyle S. Burger ${ }^{1}$ and Laura A. Berner ${ }^{2}$ \\ ${ }^{1}$ Department of Nutrition, University of North Carolina at Chapel Hill, Chapel Hill NC \\ ${ }^{2}$ Department of Psychology, Drexel University, Philadelphia, PA
}

\begin{abstract}
Adequate energy intake is vital for the survival of humans and is regulated by complex homeostatic and hedonic mechanisms. Supported by functional MRI (fMRI) studies that consistently demonstrate differences in brain response as a function of weight status during exposure to appetizing food stimuli, it has been posited that hedonically driven food intake contributes to weight gain and obesity maintenance. These food reward theories of obesity are reliant on the notion that the aberrant brain response to food stimuli relates directly to ingestive behavior, specifically, excess food intake. Importantly, functioning of homeostatic neuroendocrine regulators of food intake, such as leptin and ghrelin, are impacted by weight status. Thus, data from studies that evaluate the effect of weight status on brain response to food may be a result of differences in neuroendocrine functioning and/or behavior. In the present review, we examine the influence of weight and weight change, exogenous administration of appetitive hormones, and ingestive behavior on BOLD response to food stimuli.
\end{abstract}

\section{Keywords}

functional MRI; reward; obesity; appetitive hormones; food intake; ingestive behavior

\section{Introduction}

Nearly $30 \%$ of American adults are able to maintain a healthy weight (defined as body mass index (BMI) < 25.1) despite living in an environment that relentlessly presents large portions of energy-dense, highly palatable foods [1]. The excess adiposity tissue of the remaining $70 \%$ of Americans, who are overweight or obese, places them at higher risk for diseases such as atherosclerotic cerebrovascular disease, coronary heart disease, cancer, hyperlipidemia, hypertension, and diabetes mellitus, which result in as many as 300,000 annual deaths [2]. The dramatic rise and maintenance of the prevalence of obesity in the majority, but not the entirety of the population indicate that individual differences in the determinants of ingestive behavior play a role in weight regulation.

Address correspondence: Kyle S. Burger, 2204 McGravran-Greenberg Hall, CB 7461, Chapel Hill, NC 27599, Phone: 919-843-9933, kyle_burger@unc.edu. 
The determinants of ingestive behavior are frequently thought to involve parallel systems that interact with the external food environment to influence food intake [3, 4]. First, homeostatic mechanisms, via appetitive hormones (e.g., leptin, ghrelin), act on neural circuitry converging through hypothalamus to stimulate or inhibit feeding in an effort to maintain energy balance and a healthy weight. Evidenced by the prevalence of overweight and obesity, this system is susceptible to failure. As a result, more research attention has focused on the impact of hedonic aspects of food and food cues on the brain's reward, attentional, and behavioral control circuitries. Theorists posit that neuropsychological constructs such as aberrant reward-related responses to food intake and/or cues override homeostatic processes, resulting in excess adipose tissue and weight gain (e.g., [3]).

Advances in neuroimaging techniques, particularly functional magnetic resonance imaging (fMRI) allow for the study of whole brain blood-oxygen level dependent (BOLD) response, a proxy used to indicate activity, during exposure various food stimuli in humans without use of contrast agents. This evolving technique has provided valuable insight into the neural correlates of ingestive behavior and weight regulation. Yet, some of the most prominent theories of aberrant neural responses to food reward and obesity appear to be in conflict. For example, obesity has been described as both a problem characterized by hyper- and hyporesponsivity of the reward circuitry [5-7]. Similarly, it has been suggested that these seemingly incompatible theories can operate concurrently and the valence of the neural response is contingent on the specific type of stimulus (i.e., the response to predictive cue versus actual receipt of a palatable tastant [8]). Independent of the exact hypothesis, all food reward based theories of obesity rely on the notion that the observed aberrant neural response to food stimuli relates to ingestive behavior. For example, it has been posited hypersensitivity to food cues places individuals at greater risk for overeating [7], presumably because these individuals are more susceptible to environmental food cues and eat more frequently (i.e., decreased satiety; Fig 1.). Likewise, it has been suggested that those with a deficient neural response to food in reward-related regions consume excess food to compensate for a lack of reward or attenuated reinforcement [5], which could likely result in greater intake during a single eating occasion (i.e., delayed satiation; Fig 1.). To date, most studies use weight status or weight change when examining BOLD response to food stimuli and have yet to directly examine the neural underpinnings of ingestive behavior, i.e., the neurobehavioral aspects that contribute to body weight.

Examining the neural responses to food stimuli that contribute to overeating behavior may prove critical, as changes in physiology, particularly neuroendocrine functioning, are associated with weight change. These alterations in neuroendocrine functioning may confound examinations of obese versus lean individuals that are aimed at understanding the etiology of obesity. Further, because habitual overeating resulting in a positive energy balance precedes initial weight gain, direct examination of the neural correlates of ingestive behavior provides insight into obesity risk factors; whereas assessing brain response to food stimuli in obese versus lean individuals or in obese individuals before and after weight change may elucidate obesity maintenance factors. Improved knowledge of neural risk factors for weight gain and differentiation of these risk factors from neural consequences of excess adipose tissue are needed, especially as data from food-related fMRI studies begin to serve as outcome measures of behavioral obesity prevention and treatment research. This 
review first examines human fMRI studies focused on brain-based correlates of obesity and weight change, briefly surveys studies examining the influence of select appetitive hormones on BOLD response to food stimuli, as well as studies focused on relation of acute and the habitual ingestive behavior to BOLD response to food stimuli. Lastly, we review emerging factors that are related to aspects of hedonically driven food intake.

\section{BOLD response to food stimuli as a function of weight status}

To date, fMRI studies assessing the relation between weight and BOLD response to food stimuli typically use one of three types of designs: 1) cross-sectional studies comparing overweight and/or obese versus lean individuals, 2) prospective 'brain-as-predictor' of weight change designs or 3) within-subject repeated scan designs. Each of these designs provides unique insight into the neural underpinnings, consequences, and maintenance factors of obesity.

\subsection{Cross-sectional evaluation of BOLD response in obese versus lean humans}

One of the most replicated findings in the neuroimaging of obesity is the elevated neural response to images of palatable and energy-dense foods seen in obese versus lean humans. When compared to their lean counterparts, overweight and obese individuals show significantly more activity in the striatum, insula, orbitofrontal cortex (OFC), and amygdala [9-17], all regions thought to encode the reward value of stimuli and consequently influence future behavior [18]. When exposed to visual food images or cues predicting palatable food receipt, obese versus lean individuals also show greater activation in brain regions associated with visual processing and attention (visual and anterior cingulate cortices), the encoding of stimulus salience (precuneus), in the primary taste cortex (anterior insula, frontal operculum), and oral somatosensory regions (postcentral gyrus, rolandic operculum; [9-17]). In contrast, in several studies obese versus lean individuals showed less activity in the striatum in response to receipt of palatable food relative to a tasteless solution [17, 19-22], though one study failed to replicate these findings [16].

These data indicate that overweight individuals show aberrant neural responses to food stimuli, specifically, an elevated striatal response to anticipatory cues (e.g., images, predictive cues) and decreased striatal response during consumption. As a result, these findings support both the hyper- and hypo-reward theories of obesity [5-7]). Critically, by nature of study design alone, cross-sectional investigations provide no ability to draw inferences regarding the temporal precedence of weight status and observed neural effects and thus equally support the notions that the BOLD response patterns are an underlying cause of weight gain or a consequence of habitual overeating and/or obesity. Further, these data and theories inherently presume a static neural response despite the high likelihood of neuroadaptations associated with repeated consumption of rewarding foods and recurring exposure to the associated food cues, as well as the known altered neuroendocrine functioning that is associated with obesity. 


\subsection{Prospective evaluation of BOLD response and weight change}

Prospective studies provide insight into preexisting risk factors for weight gain relative to consequences of or maintenance factors associated with obesity. For example, neural activity can be used to predict subsequent behaviors in a 'brain-as-predictor' methodology wherein BOLD response to relevant stimuli is assessed at baseline and tested as a predictor of an outcome measure of interest assessed in the future [23]. Using a similar approach, individuals who showed greater activation in the OFC in response to a cue predicting palatable food gained more weight over one year [24]. Concordantly, ventral striatum and anterior cingulate activity in response to appetizing food images predicted weight gain at 6 month follow-up [25]. The authors concluded that individuals with elevated responses to food images in these reward and attention-related regions are at risk for future weight gain. Interestingly, both studies' samples included individuals who were overweight and obese at baseline, whereas, the same reward-related neural responses to food stimuli did not predict weight gain in a sample of very lean youth (mean BMI $20.8 \pm 1.9$ ) at one-year follow-up [26]. Of note, only $\sim 12 \%$ of this healthy-weight sample transitioned to overweight/obese status in the follow-up period, which may have resulted in a ceiling effect that prevented accurate evaluation of predictors of unhealthy weight gain [26].

These findings have implications not only for weight gain in the natural environment, but also for response to weight loss intervention: greater striatum and insula activity when viewing energy-dense foods at baseline was found to predict poorer outcome in a weight loss program over 9-month follow-up [27], suggesting that individuals with elevated responsivity to appetizing food cues in these regions are less likely to respond to a behavioral weight loss intervention. Collectively, results of these studies support the theory that obesity or high risk for obesity is associated with hyper-responsivity to food cues in brain regions thought to encode aspects of reward and taste.

Studies evaluating BOLD response to palatable food receipt as a predictor for weight gain have revealed somewhat less consistent effects. Striatum, ventral palldium and midbrain response to milkshake receipt was positively related to weight gain at one-year follow-up in a sample containing over- and healthy-weight participants [28]. Increased dorsal striatum responses to milkshake receipt also predicted weight gain at one-year follow-up, but only in individuals without an A1 polymorphism of the TaqIA allele [20]. Those individuals with at least one A1 variant showed an inverse relation between striatal response to food receipt and weight gain [20].

Taken together, fMRI studies evaluating the relation between BOLD response to palatable food receipt and obesity consistently show a reduced response with increasing BMI; however, prospective studies are inconclusive, suggesting the reduced response may be individual risk factor in some individuals, but not others, or a consequence of adiposity or repeated overeating rather than an innate risk factor for weight gain. Further, although 'brain-as-predictor' studies represent a unique opportunity to draw inferences regarding risk factors for future weight gain, the majority of these prospective studies have included individuals who are already overweight or obese. Consequently, the results of these investigations aid in the identification of obesity maintenance factors or continued weight 
gain risk factors, but cannot be used to draw inferences about initial vulnerability factors for weight gain.

\subsection{Repeated measures of BOLD response and weight change}

While the abovementioned 'brain-as-predictor' studies provide insight into risk factors for future weight gain, they cannot provide information regarding neuroapdations associated with weight change critical to elucidating the temporal precedence of aberrant brain activation patterns weight gain, and obesity. To date, few repeated-measures fMRI studies are available. One such study revealed that change in adipose tissue and BMI over a 6month period was positively related to activity in the insula and visual cortex activity during exposure of appetizing food images, relative to baseline scans [29]. Interestingly, weight gain over a 6-month period was associated with reduced striatal response to palatable food receipt relative to both baseline and to women who maintained a stable weight over the 6month period [30]. Together, these investigations demonstrate neuroadaptations associated with weight change, which are consistent with results seen in the above-mentioned crosssectional and prospective studies. Specifically, these data indicate that change in response to food cues in attention and gustatory regions are positively associated with weight change, whereas change in striatal response to food receipt is inversely related to weight change. Nonetheless, changes in adipose tissue levels and related appetitive hormone functioning alterations with weight change may influence these findings.

\section{Neuroendocrine function and neural response}

More comprehensive reviews detail the mechanisms through which endocrine functioning influences hunger and satiety to maintain homeostasis and have documented alterations in hormone levels in obese individuals [31-33]. Although homeostatic mechanisms of food intake are distinct from aspects of food reward, the degree to which homeostatic and hedonic systems interact to influence intake has yet to be fully understood. Recent studies have utilized fMRI to evaluate the impact of exogenous administration of hormones involved in homeostatic regulation of intake (e.g., leptin, ghrelin, GLP-1, PYY and insulin) on BOLD response to food stimuli. These investigations permit more comprehensive understanding of the neuroscience underlying aberrant neural activation in obesity. Of note, much of the research directly assessing neuroendocrine levels and neural activation have thus far included only healthy-weight individuals, and further study including endocrine assessment and exogenous administration in overweight and obese individuals is needed to elucidate the complex effects of elevated weight status.

\subsection{Leptin}

The adipokine leptin, synthesized in adipose cells, conveys information to the central nervous system about long-term energy stores and inhibits activity of the appetite stimulants neuropeptide $\mathrm{Y}$ and agouti-related peptide in the hypothalamus, thereby acting as an indirect anorectic signal [34]. Circulating leptin levels are positively related to percent body fat [35, 36], however the uptake of leptin into cerebrospinal fluid is less efficient among those with high circulating leptin (as seen in obesity) [37]. This inefficiency suggests the effectiveness of leptin signaling in obesity is compromised and obese individuals may be leptin resistant 
$[33,38]$; therefore, observed aberrant neural responses of obese individuals compared to lean individuals or obese individuals pre-weight loss may be related to leptin resistance associated with obese weight status. Leptin has been associated with decreases in acute intake [39]. FMRI studies demonstrate that in lean and overweight individuals with congenital leptin deficiency, leptin replacement reduces insula and striatopallidal activation and increases prefrontal cortex activation in response to images of palatable foods [40, 41]; changes in neural activation in these areas are theoretically consistent with reduced appetitive drive and increased inhibitory control.

\subsection{Peptide YY and glucagon-like peptide 1}

Similar to leptin, the gut hormones peptide YY (PYY) and glucagon-like peptide 1 (GLP-1) are thought to act by reducing appetite and signaling meal termination. Circulating PYY is negatively correlated with BMI, however, following PYY infusion decreased meal intake observed in both obese and lean individuals [42]. This suggests that PYY deficiency, not inefficiency in uptake or resistance is associated with obesity. Exogenous administration of GLP- $1_{7-36}$ amide leads to a reduction in appetite and ad libitum energy intake in both lean and obese individuals $[43,44]$. However, the release of GLP-1 in response to food intake in obese relative to lean individuals may be attenuated $[45,46]$ and higher GLP-1 levels may be required to produce anorectic effects in obese individuals, suggesting GLP-1 insensitivity [43]. Further, following exogenous administration of $\mathrm{PYY}_{3-36}$ and GLP-1 ${ }_{7-36}$ amide, both independently and in combination, in fasted, healthy-weight individuals, reductions were observed in BOLD activity in the striatum, insula and OFC in response to palatable food images [47], suggesting downstream effects of these hormones on regions commonly associated with rewarding aspects of food stimuli. These results may in part explain fMRI findings comparing lean and obese participants; specifically, obese individuals may present with lower circulating PYY and insensitivity to GLP-1 which would, in theory, result in increased activity in the striatum, insula and OFC during exposure to food images. Further, among obese individuals, increases in postprandial GLP-1 were associated with greater activation, as measured by positron emission tomography (PET) in a region associated with satiety, the left dorsolateral PFC [48]. Attenuated postprandial GLP-1 response in obese individuals may therefore modulate reductions in satiety and reduced PFC activation.

\subsection{Ghrelin}

Ghrelin is a peptide synthesized in the gastrointestinal tract that acts on the hypothalamic NPY/AgRP orexigenic pathway resulting in initiation of feeding [49, 50]. Lower circulating ghrelin levels are seen in obese versus lean individuals [51], yet obese individuals do not show a postprandial decrease in ghrelin levels [52], thereby likely increasing the risk for excess energy intake. In support of this hormone-behavior connection, ghrelin administration in normal-weight individuals leads to increased energy intake [53,54] and increased BOLD response in the striatum, amygdala, $\mathrm{OFC}$, and anterior insula during exposure to appetizing food images [55]. Further, a recent study of lean individuals homozygous for the FTO allele associated with high risk for obesity, reported attenuated postprandial acyl-ghrelin decreases, and a smaller difference in BOLD response in the anterior insula, striatum, lateral OFC to high-calorie minus-low-calorie food picture contrasts in the fed compared to fasted state [56]. This effect in the OFC and striatum was 
moderated by fasting plasma acyl-ghrelin levels. Thus, fMRI studies comparing obese versus lean individuals pre- and post meal may be influenced by abnormal ghrelin levels associated with genetic risk for or obese weight status.

\subsection{Insulin}

Insulin is secreted from the pancreas immediately following glucose consumption and normally has an anorectic effect, but baseline insulin levels are elevated in overweight and obese individuals [57]. In healthy-weight individuals, intranasal administration of insulin, which permits isolation of the action of insulin in the central nervous system, reduced BOLD activation in response to food images in the bilateral fusiform gyrus and the right hippocampus, temporal superior cortex, and middle frontal cortex [58]. Further, in normalweight men, greater post-meal increases in plasma insulin concentrations were associated with reduced activation, as measured by PET, in the insula and orbitofrontal cortex [59]. A resting state fMRI study including obese and lean individuals demonstrated a positive relation between functional connectivity strength in the left OFC and right putamen and fasting insulin levels and a negative correlation between activity in these regions and insulin sensitivity [60]. Altered insulin levels and signaling associated with obesity may therefore contribute to altered neural activation in reward areas in fMRI studies of these individuals.

The above appetitive hormones are known to have varied plasma concentrations and/or compromised effectiveness in overweight and obese individuals and exogenous administration moderates BOLD response to food stimuli in regions thought to encode aspects of hedonic eating (Table 1). Continued study of hormones in conjunction with fMRI will further elucidate the brain networks that modulate intake and may contribute to the etiology and maintenance of obesity.

\section{Ingestive behavior \& BOLD response to food}

Altered neuroendocrine functioning, in part related to increased adipose tissue, may impact findings from human fMRI studies evaluating response to food stimuli; however, the habitual eating behavior that leads to and maintains obesity may play an equally significant role in altering neural repsonsivity. The BOLD response patterns, i.e., heightened neural response to cues and reduced response to receipt, parallel those seen habitual substance users, irrespective of weight status, when exposed to relevant stimuli [61-63]. Independent of the notion of 'food addiction,' the parallel aberrant neural responses to exposure to relevant stimuli in substance use disorders and obesity suggest that the process of repeated behavior contributes to aberrant neural responses. Critically, individuals must consistently consume energy beyond what they expend to initiate weight gain. Thus, examining neural correlates of both acute and longer-term ingestive behavior prior to onset of overweight or obese weight status provides insight into the factors contributing to excess intake in isolation from the confounds of neuroendocrine functioning associated with obesity.

\subsection{Acute ingestive behavior \& BOLD response to food stimuli}

Few studies have assessed the acute relation between BOLD response and ingestive behavior. Midbrain and medial OFC activity in response to milkshake receipt (small tastes; 
$\sim 30 \mathrm{~mL}$ over the scanning session) positively predicted subsequent ad libitum milkshake consumption [64]. Of note, this sample included lean and overweight individuals, however BMI was included as a covariate in all analyses. Results of a second study indicate BOLD response in the ventral striatum during exposure to food images positively predicts later snack consumption, and striatal activity was not significantly related to BMI [65].

Collectively these studies indicate that BOLD activity in regions thought to encode reward and motivation in response to food receipt and images positively predict subsequent food intake. This supports with the theories that hypersensitivity to food reward may contribute to the development of regular overeating, placing the individual at higher risk for developing obesity.

\subsection{Habitual ingestive behavior \& BOLD response to food stimuli}

In addition to associations with acute food intake in close proximity to scanning, studies integrating more long-term eating behavior data have further clarified potential relations between neural activation and the repeated behavior that leads to and maintains obesity. Using objectively measured energy intake over a two-week period in lean adolescents, a positive relation was observed between energy intake beyond basal metabolic needs and BOLD response during cues predicting food receipt in regions thought to encode visual processing and attention (visual and anterior cingulate cortices), salience (precuneus), as well as the primary gustatory cortex (frontal operculum) and (reward/motivation) striatum [66]. Further, habitual soft drink consumers also showed greater precuneus activity when shown advertisements promoting the brand of their preferred soft drink, relative to their BMI-matched non-soda consuming counterparts [67]. This pattern of activity is analogous to previous cross-sectional studies comparing obese relative to lean individuals in response to food images and cues (e.g., [12-15]), suggesting that repeated ingestive behavior, independent of weight status, contributed to the increased response to food images and advertisements (Table 2).

As previously noted, a reduced response to palatable food receipt in regions associated with reward (e.g., striatum, amygdala) and gustatory (e.g., insula, frontal operculum) processing has been observed in cross-sectional studies comparing obese versus lean individuals [17, 19-22]. Consistent with the notion that a key difference between these lean and obese participants was the obese groups' repeated consumption of highly palatable foods, greater frequency of artificial sweetener use was related to decreased striatal response during intake of a saccharin (a nonnutritive sweetener) solution [68], as well as decreased response in the insula and amygdala during sucrose solution intake [69]. Further, frequency of ice cream consumption has been found to be inversely related to ventral striatum, insula and ventromedial prefrontal cortex response during milkshake receipt [70]. Collectively these data indicate that regular, repeated consumption of sweetened foods is related to a reduced BOLD response during intake of a similarly sweetened tastant. Critically, as two of the three samples included in these studies were lean, these results are independent of overweight status and compromised neuroendocrine functioning (Table 2).

The above findings indicate that repeated intake of highly palatable foods might contribute to further energy intake as well as being related to aberrant BOLD responses to food cues/ 
images. Activity in these studies mirror results from studies comparing obese vs. lean controls and prospective evaluations of BOLD response and weight change. Thus, these neural patterns precede weight gain and may represent obesity risk factors. While these findings provide insight the temporal relation between obesity, weight gain and aberrant neural responses to food stimuli, the exact temporal precedence remains largely unclear.

\subsection{Ingestive behavior \& food composition}

An interesting caveat that is gaining more of a presence in the food reward literature is the composition of food consumed; specifically the energy density, fat and sugar content of palatable foods as it relates to BOLD response, and weight regulation. As fat and sugar are most often included in highly palatable foods and implicated in obesity, investigations have focused on neural effects of these macronutrients. Increasing fat concentrations of tastants have been shown to elicit activity in anterior insula, frontal operculum and secondary somatosensory cortex, anterior cingulate cortex, and amygdala [71, 72]. The anterior insula and ventral anterior cingulate cortex both respond to oral fat (independently of its viscosity) and sugar intake [72]. Increasing the sugar content of a tastant elicited greater activity in the insula and rolandic operculum, whereas an increase in fat did not fat did not result in a change in BOLD response [73]. Therefore, the high-sugar content, relative to fat content in palatable foods may elicit a greater neural response, and repeated consumption of particularly high-sugar foods may play a larger role the neural abnormalities observed in reward regions. This finding is particularly relevant in light of evidence that the sugar content of foods available in the environment has only increased over the last 40 years, coinciding with the rise in obesity [74]. However, fat provides more calories than sugar per gram (fat $9 \mathrm{kcals} / \mathrm{g}$ vs. sugar $4 \mathrm{kcals} / \mathrm{g}$ ), so it is reasonable hypothesis that fat intake may more readily impact weight status. Given that fat and sugar are frequently paired in energy dense foods, it is an interesting notion to think that frequent high sugar intake may alter neural response to food, while the associated kcals from fat may drive excess caloric intake, both driving weight gain.

Beyond disparate impacts on gustatory and striatal regions, the interplay of sugar and fat effects on homeostatic processes in the hypothalamus may in turn affect subsequent eating behavior, particularly that of highly palatable foods. For example, a high-carbohydrate diet increases neuropeptide (NPY) expression, and a high-fat diet increases expression of galanin, another neuropeptide, [75] while reducing NPY expression [76]. This may be a result of galanin inhibiting NPY in the hypothalamus [77]. In turn, increases in galanin stimulate further fat intake, while increased neuropeptide Y (NPY) stimulates further carbohydrate intake [76]. Thus, both homeostatic and hedonic effects of fat and sugar may contribute to further excess consumption of these foods and ultimately weight gain.

\section{Discussion}

Here we reviewed fMRI studies that examined BOLD response to food and food cues in three different dependent measures: i) weight status and change; ii) peripheral administration of appetitive hormones altered in obesity; and iii) assessments of acute and habitual ingestive behavior. Overall, data from these three study designs suggest increased BOLD response to food cues (images and during anticipation) is positively related to weight. 
During exposure to food cues obese versus lean individuals show greater activity in regions commonly associated with reward and/or motivation (i.e., striatum, pallidum, midbrain, $\mathrm{OFC}$ ), regions thought to encode visual processing and attention (visual and anterior cingulate cortices), salience (precuneus), and gustatory (insula, frontal operculum) and oral somatosensory (postcentral gyrus) processing. Prospective and behavioral data further support the above findings: OFC, striatal and insular activity in response to food cues were positively predictive of weight gain or poor outcome in a weight loss program [24, 25, 27], and changes in body fat were positively related to striatal response to appetizing food images [29]. Of note, obese relative to lean individuals are also likely to present altered neuroendocrine functioning such as, leptin and insulin resistance, decreased circulating PYY and leptin levels. Peripheral administration of these appetitive hormones in moderates the BOLD response to palatable food images in a similar manner seen when comparing obese versus lean, suggesting neuroendocrine functioning may significantly interact with foodrelated responsivity as detected by BOLD signal. Importantly, this effect can only occur after excess consumption of food and weight gain. As such, appetitive hormone alterations may also serve as obesity maintenance factors.

Obese individuals also have shown a reduced striatal response during receipt of palatable food in five independent samples [17, 19-22]. A decreased striatal response to food receipt is associated with weight gain [30] and habitual consumption of sweet foods [68-70]. In seeming contrast, striatal response to food receipt is positively predicts weight gain [20, 28] in samples including both healthy- and overweight individuals, and striatal activity during milkshake receipt positively predicts subsequent ad libitum milkshake intake [64]. This pattern of results in suggests that the attenuated response to receipt is not innate risk factor for weight gain, for most, but may be acquired through the process of regular consumption of highly palatable foods and contribute to unhealthy weight maintenance. In contrast, greater activity in regions associated with attention, salience, reward/motivation and gustatory processing during exposure to food cues are consistently associated with obesity, propensity for weight gain, as well as greater acute and habitual food intake, indicating this activity pattern associated with cues may serve as a risk factor for weight gain as well as an obesity maintenance factor.

This notion of initial hyper-responsivity to food leading to overeating which, in turn contributes to a increased valuation of sensitized cues and an attenuated response to food intake is supported by animal models [78, 79], and a similar notion has been posited in humans [8]. Animal models show phasic dopamine release initially occurs upon palatable food receipt and shifts to fire to an associated cue after repeated pairings [78]. Further, this process may result in sensitized (food) cues that inform goal directed behavior [79], and the repeated challenges to brain reward circuitry by habitually consuming palatable foods could disrupt the allostasis of this system resulting in further reward dysregulation [80].

An alternative, yet closely related construct that likely plays a role in the relations among food reward, frequent consumption and weight gain is impulsivity. For example, obese versus lean individuals show behavioral inhibition deficits and immediate reward bias for food reward [81, 82]. FMRI studies show that obese women showed less activation in prefrontal brain regions associated with executive functioning (middle and inferior frontal 
gyri) during a general delay discounting task [83] and a similar neural response pattern predicted future weight gain [84]. Overweight relative to lean adolescents demonstrated behavioral evidence of inhibitory control deficits and reduced activation of prefrontal inhibitory regions during a food specific go/no-go task, a variant of a classic inhibitory control assessment [85]. These data are supported by a study examining the relation between neural response to food images and eating behavior. Specifically, in a predominately healthy-weight sample, activity in the right dorsolateral prefrontal cortex (a region associated with inhibitory control) during exposure to appetizing food images was inversely predictive of ad libitum intake at a subsequent meal [86].

Certainly an expanded review of the literature including more in-depth review of PET imaging studies, reviews using bariatric surgery, and drawing from animal models can provide additional insight to the questions discussed here. We refer readers to excellent reviews directly addressing these topics [87-89]. Despite rapid advances in the study of neural response to food stimuli, critical questions remain: which of aberrant responses to food stimuli are predisposing vulnerability factors and which are consequences of unhealthy ingestive behavior? Moreover, can the identification of individual neurobehavioral risk factors for weight gain inform effective interventions? Functional neuroimaging has the potential to serve as an invaluable tool in the investigation of interacting homeostatic and hedonic mechanisms that guide ingestive behavior. Additional use of controlled, prospective study designs coupled with objective assessments of eating behavior and assessments of hormone will provide critical knowledge regarding ingestive behavior and obesity.

\section{Acknowledgments}

This manuscript contains work presented during the 2013 Annual Meeting of the Society for the Study of Ingestive Behavior, July 30 - August 3, 2013. The SSIB meeting was made possible in part by generous unrestricted donations from its sponsors. This review was also supported in part by grant F31MH097406 (LAB) from the National Institute of Mental Health.

\section{References}

1. Flegal KM, Carroll MD, Kit BK, Ogden CL. Prevalence of Obesity and Trends in the Distribution of Body Mass Index Among US Adults, 1999-2010. Jama-Journal of the American Medical Association. 2012; 307:491-7.

2. Luppino FS, de Wit LM, Bouvy PF, Stijnen T, Cuijpers P, Penninx BWJH, et al. Overweight, Obesity, and Depression A Systematic Review and Meta-analysis of Longitudinal Studies. Archives of General Psychiatry. 2010; 67:220-9. [PubMed: 20194822]

3. Lutter M, Nestler EJ. Homeostatic and Hedonic Signals Interact in the Regulation of Food Intake. Journal of Nutrition. 2009; 139:629-32. [PubMed: 19176746]

4. Morton G, Cummings D, Baskin D, Barsh G, Schwartz M. Central nervous system control of food intake and body weight. Nature. 2006; 443:289-95. [PubMed: 16988703]

5. Wang GJ, Volkow ND, Logan J, Pappas NR, Wong CT, Zhu W, et al. Brain dopamine and obesity. Lancet. 2001; 357:354-7. [PubMed: 11210998]

6. Davis C, Strachan S, Berkson M. Sensitivity to reward: implications for overeating and overweight. Appetite. 2004; 42:131-8. [PubMed: 15010176]

7. Berridge KC, Ho CY, Richard JM, DiFeliceantonio AG. The tempted brain eats: pleasure and desire circuits in obesity and eating disorders. Brain research. 2010; 1350:43-64. [PubMed: 20388498] 
8. Stice E, Yokum S, Burger KS, Epstein LH, Small DM. Youth at Risk for Obesity Show Greater Activation of Striatal and Somatosensory Regions to Food. Journal of Neuroscience. 2011; 31:4360-6. [PubMed: 21430137]

9. Dimitropoulos A, Tkach J, Ho A, Kennedy J. Greater corticolimbic activation to high-calorie food cues after eating in obese vs. normal-weight adults. Appetite. 2012; 58:303-12. [PubMed: 22063094]

10. Frankort A, Roefs A, Siep N, Roebroeck A, Havermans R, Jansen A. Reward activity in satiated overweight women is decreased during unbiased viewing but increased when imagining taste: an event-related fMRI study. International Journal of Obesity. 2012; 36:627-37. [PubMed: 22064161]

11. Bruce A, Holsen L, Chambers R, Martin L, Brooks W, Zarcone J, et al. Obese children show hyperactivation to food pictures in brain networks linked to motivation, reward and cognitive control. International Journal of Obesity. 2010; 34:1494-500. [PubMed: 20440296]

12. Nummenmaa L, Hirvonen J, Hannukainen JC, Immonen H, Lindroos MM, Salminen P, et al. Dorsal Striatum and Its Limbic Connectivity Mediate Abnormal Anticipatory Reward Processing in Obesity. Plos One. 2012; 7

13. Rothemund Y, Preuschhof C, Bohner G, Bauknecht HC, Klingebiel R, Flor H, et al. Differential activation of the dorsal striatum by high-calorie visual food stimuli in obese individuals. Neuroimage. 2007; 37:410-21. [PubMed: 17566768]

14. Martin LE, Holsen LM, Chambers RJ, Bruce AS, Brooks WM, Zarcone JR, et al. Neural mechanisms associated with food motivation in obese and healthy weight adults. Obesity. 2009; 18:254-60. [PubMed: 19629052]

15. Stoeckel LE, Weller RE, Cook EW III, Twieg DB, Knowlton RC, Cox JE. Widespread rewardsystem activation in obese women in response to pictures of high-calorie foods. Neuroimage. 2008; 41:636-47. [PubMed: 18413289]

16. Ng J, Stice E, Yokum S, Bohon C. An fMRI study of obesity, food reward, and perceived caloric density. Does a low-fat label make food less appealing? Appetite. 2011; 57:65-72. [PubMed: 21497628]

17. Stice E, Spoor S, Bohon C, Veldhuizen MG, Small DM. Relation of Reward From Food Intake and Anticipated Food Intake to Obesity: A Functional Magnetic Resonance Imaging Study. Journal of Abnormal Psychology. 2008; 117:924-35. [PubMed: 19025237]

18. Beaver JD, Lawrence AD, Van Ditzhuijzen J, Davis MH, Woods A, Calder AJ. Individual differences in reward drive predict neural responses to images of food. Journal of Neuroscience. 2006; 26:5160-6. [PubMed: 16687507]

19. Babbs RK, Sun X, Felsted J, Chouinard-Decorte F, Veldhuizen MG, Small D. Decreased caudate response to milkshake is associated with higher body mass index and greater impulsivity. Physiology \& behavior. 2013

20. Stice E, Spoor S, Bohon C, Small DM. Relation between obesity and blunted striatal response to food is moderated by TaqIA A1 allele. Science. 2008; 322:449-52. [PubMed: 18927395]

21. Frank GK, Reynolds JR, Shott ME, Jappe L, Yang TT, Tregellas JR, et al. Anorexia nervosa and obesity are associated with opposite brain reward response. Neuropsychopharmacology. 2012; 37:2031-46. [PubMed: 22549118]

22. Green E, Jacobson A, Haase L, Murphy C. Reduced nucleus accumbens and caudate nucleus activation to a pleasant taste is associated with obesity in older adults. Brain research. 2011; 1386:109-17. [PubMed: 21362414]

23. Berkman ET, Falk EB. Beyond Brain Mapping Using Neural Measures to Predict Real-World Outcomes. Current Directions in Psychological Science. 2013; 22:45-50. [PubMed: 24478540]

24. Yokum S, Ng J, Stice E. Attentional Bias to Food Images Associated With Elevated Weight and Future Weight Gain: An fMRI Study. Obesity. 2011; 19:1775-83. [PubMed: 21681221]

25. Demos KE, Heatherton TF, Kelley WM. Individual differences in nucleus accumbens activity to food and sexual images predict weight gain and sexual behavior. The Journal of Neuroscience. 2012; 32:5549-52. [PubMed: 22514316] 
26. Stice E, Yokum S, Burger KS. Elevated Reward Region Responsivity Predicts Future Substance Use Onset But Not Overweight/Obesity Onset. Biological Psychiatry. 2013; 73:869-76. [PubMed: 23312561]

27. Murdaugh DL, Cox JE, Cook EW III, Weller RE. fMRI reactivity to high-calorie food pictures predicts short- and long-term outcome in a weight-loss program. Neuroimage. 2012; 59:2709-21. [PubMed: 22332246]

28. Geha PY, Aschenbrenner K, Felsted J, O'Malley SS, Small DM. Altered hypothalamic response to food in smokers. The American journal of clinical nutrition. 2013; 97:15-22. [PubMed: 23235196]

29. Cornier MA, Melanson EL, Salzberg AK, Bechtell JL, Tregellas JR. The effects of exercise on the neuronal response to food cues. Physiology \& Behavior. 2012; 105:1028-34. [PubMed: 22155218]

30. Stice E, Yokum S, Blum K, Bohon C. Weight Gain Is Associated with Reduced Striatal Response to Palatable Food. Journal of Neuroscience. 2010; 30:13105-9. [PubMed: 20881128]

31. Abizaid A, Liu ZW, Andrews ZB, Shanabrough M, Borok E, Elsworth JD, et al. Ghrelin modulates the activity and synaptic input organization of midbrain dopamine neurons while promoting appetite. Journal of Clinical Investigation. 2006; 116:3229-39. [PubMed: 17060947]

32. Campfield LA, Smith FJ, Guisez Y, Devos R, Burn P. Recombinant mouse OB protein: evidence for a peripheral signal linking adiposity and central neural networks. Science. 1995; 269:546-9. [PubMed: 7624778]

33. Schwartz MW, Woods SC, Porte D, Seeley RJ, Baskin DG. Central nervous system control of food intake. Nature. 2000; 404:661-71. [PubMed: 10766253]

34. Williams KW, Scott MM, Elmquist JK. From observation to experimentation: leptin action in the mediobasal hypothalamus. American Journal of Clinical Nutrition. 2009; 89:985S-90S. [PubMed: 19176744]

35. Considine RV, Sinha MK, Heiman ML, Kriauciunas A, Stephens TW, Nyce MR, et al. Serum immunoreactive leptin concentrations in normal-weight and obese humans. New England Journal of Medicine. 1996; 334:292-5. [PubMed: 8532024]

36. Havel PJ, KasimKarakas S, Mueller W, Johnson PR, Gingerich RL, Stern JS. Relationship of plasma leptin to plasma insulin and adiposity in normal weight and overweight women: Effects of dietary fat content and sustained weight loss. Journal of Clinical Endocrinology \& Metabolism. 1996; 81:4406-13. [PubMed: 8954050]

37. Schwartz MW, Peskind E, Raskind M, Boyko EJ, Porte D. Cerebrospinal fluid leptin levels: Relationship to plasma levels and to adiposity in humans. Nature Medicine. 1996; 2:589-93.

38. Enriori PJ, Evans AE, Sinnayah P, Cowley MA. Leptin resistance and obesity. Obesity. 2006; $14: 254-8$.

39. Klok M, Jakobsdottir S, Drent M. The role of leptin and ghrelin in the regulation of food intake and body weight in humans: a review. Obesity reviews. 2007; 8:21-34. [PubMed: 17212793]

40. Baicy K, London ED, Monterosso J, Wong ML, Delibasi T, Sharma A, et al. Leptin replacement alters brain response to food cues in genetically leptin-deficient adults. Proceedings of the National Academy of Sciences. 2007; 104:18276-9.

41. Farooqi IS, Bullmore E, Keogh J, Gillard J, O'Rahilly S, Fletcher PC. Leptin regulates striatal regions and human eating Behavior. Science. 2007; 317:1355. [PubMed: 17690262]

42. Batterham RL, Cohen MA, Ellis SM, Le Roux CW, Withers DJ, Frost GS, et al. Inhibition of food intake in obese subjects by peptide YY3-36. New England Journal of Medicine. 2003; 349:941-8. [PubMed: 12954742]

43. Näslund E, Barkeling B, King N, Gutniak M, Blundell J, Holst J, et al. Energy intake and appetite are suppressed by glucagon-like peptide-1 (GLP-1) in obese men. International journal of obesity. 1999; 23:304-11. [PubMed: 10193877]

44. Verdich C, Flint A, Gutzwiller JP, Naslund E, Beglinger C, Hellstrom PM, et al. A meta-analysis of the effect of glucagon-like peptide-1 (7-36) amide on ad libitum energy intake in humans. Journal of Clinical Endocrinology \& Metabolism. 2001; 86:4382-9. [PubMed: 11549680]

45. Ranganath LR, Beety JM, Morgan LM, Wright JW, Howland R, Marks V. Attenuated GLP-1 secretion in obesity: Cause or consequence? Gut. 1996; 38:916-9. [PubMed: 8984033] 
46. Naslund E, Gutniak M, Skogar S, Rossner S, Hellstrom PM. Glucagon-like peptide 1 increases the period of postprandial satiety and slows gastric emptying in obese men. American Journal of Clinical Nutrition. 1998; 68:525-30. [PubMed: 9734726]

47. De Silva A, Salem V, Long CJ, Makwana A, Newbould RD, Rabiner EA, et al. The Gut Hormones PYY < sub $>3-36</$ sub $>$ and GLP-1< sub $>7-36$ amide $</$ sub $>$ Reduce Food Intake and Modulate Brain Activity in Appetite Centers in Humans. Cell metabolism. 2011; 14:700-6. [PubMed: 22000927]

48. Pannacciulli N, Le DSN, Salbe AD, Chen K, Reiman EM, Tataranni PA, et al. Postprandial glucagon-like peptide-1 (GLP-1) response is positively associated with changes in neuronal activity of brain areas implicated in satiety and food intake regulation in humans. Neuroimage. 2007; 35:511-7. [PubMed: 17317222]

49. Kojima M, Hosoda H, Date Y, Nakazato M, Matsuo H, Kangawa K. Ghrelin is a growth-hormonereleasing acylated peptide from stomach. Nature. 1999; 402:656-60. [PubMed: 10604470]

50. Nakazato M, Murakami N, Date Y, Kojima M, Matsuo H, Kangawa K, et al. A role for ghrelin in the central regulation of feeding. Nature. 2001; 409:194-8. [PubMed: 11196643]

51. Tschöp M, Weyer C, Tataranni PA, Devanarayan V, Ravussin E, Heiman ML. Circulating ghrelin levels are decreased in human obesity. Diabetes. 2001; 50:707-9. [PubMed: 11289032]

52. English P, Ghatei M, Malik I, Bloom S, Wilding J. Food fails to suppress ghrelin levels in obese humans. Journal of Clinical Endocrinology \& Metabolism. 2002; 87:2984. [PubMed: 12050284]

53. Druce M, Wren A, Park A, Milton J, Patterson M, Frost G, et al. Ghrelin increases food intake in obese as well as lean subjects. International journal of obesity. 2005; 29:1130-6. [PubMed: 15917842]

54. Wren A, Seal L, Cohen M, Brynes A, Frost G, Murphy K, et al. Ghrelin enhances appetite and increases food intake in humans. Journal of Clinical Endocrinology \& Metabolism. 2001; 86:5992. [PubMed: 11739476]

55. Malik S, McGlone F, Bedrossian D, Dagher A. Ghrelin modulates brain activity in areas that control appetitive behavior. Cell metabolism. 2008; 7:400-9. [PubMed: 18460331]

56. Karra E, O'Daly OG, Choudhury AI, Yousseif A, Millership S, Neary MT, et al. A link between FTO, ghrelin, and impaired brain food-cue responsivity. The Journal of clinical investigation. 2013; 123:3539. [PubMed: 23867619]

57. Björntorp, P. Obesity, atherosclerosis and diabetes mellitus. Kongre $\beta$ : Springer; 1987. p. 443-8.

58. Guthoff M, Grichisch Y, Canova C, Tschritter O, Veit R, Hallschmid M, et al. Insulin modulates food-related activity in the central nervous system. Journal of Clinical Endocrinology \& Metabolism. 2010; 95:748-55. [PubMed: 19996309]

59. Tataranni PA, Gautier JF, Chen K, Uecker A, Bandy D, Salbe AD, et al. Neuroanatomical correlates of hunger and satiation in humans using positron emission tomography. Proceedings of the National Academy of Sciences. 1999; 96:4569-74.

60. Kullmann S, Heni M, Veit R, Ketterer C, Schick F, Häring HU, et al. The obese brain: association of body mass index and insulin sensitivity with resting state network functional connectivity. Human brain mapping. 2012; 33:1052-61. [PubMed: 21520345]

61. Kenny PJ. Common cellular and molecular mechanisms in obesity and drug addiction. Nature Reviews Neuroscience. 2011; 12:638-51. [PubMed: 22011680]

62. Volkow ND, Wang GJ, Fowler JS, Telang F. Overlapping neuronal circuits in addiction and obesity: evidence of systems pathology. Philosophical Transactions of the Royal Society BBiological Sciences. 2008; 363:3191-200.

63. Tang DW, Fellows LK, Small DM, Dagher A. Food and drug cues activate similar brain regions: A meta-analysis of functional MRI studies. Physiology \& Behavior. 2012; 106:317-24. [PubMed: 22450260]

64. Nolan-Poupart S, Veldhuizen MG, Geha P, Small DM. Midbrain response to milkshake correlates with ad libitum milkshake intake in the absence of hunger. Appetite. 2013; 60:168-74. [PubMed: 23064394]

65. Lawrence NS, Hinton EC, Parkinson JA, Lawrence AD. Nucleus accumbens response to food cues predicts subsequent snack consumption in women and increased body mass index in those with reduced self-control. Neuroimage. 2012 
66. Burger KS, Stice E. Elevated energy intake is correlated with hyperresponsivity in attentional, gustatory, and reward brain regions while anticipating palatable food receipt. The American journal of clinical nutrition. 2013; 97:1188-94. [PubMed: 23595877]

67. Burger KS, Stice E. Neural responsivity during soft drink intake, anticipation, and advertisement exposure in habitually consuming youth. Obesity. 2013

68. Green E, Murphy C. Altered processing of sweet taste in the brain of diet soda drinkers. Physiology \& behavior. 2012; 107:560-7. [PubMed: 22583859]

69. Rudenga K, Small D. Amygdala response to sucrose consumption is inversely related to artificial sweetener use. Appetite. 2012; 58:504-7. [PubMed: 22178008]

70. Burger KS, Stice E. Frequent ice cream consumption is associated with reduced striatal response to receipt of an ice cream-based milkshake. American Journal of Clinical Nutrition. 2012; 95:810-7. [PubMed: 22338036]

71. Grabenhorst F, Rolls ET, Parris BA, d'Souza AA. How the Brain Represents the Reward Value of Fat in the Mouth. Cerebral Cortex. 2010; 20:1082-91. [PubMed: 19684248]

72. De Araujo IE, Rolls ET. Representation in the human brain of food texture and oral fat. The Journal of neuroscience. 2004; 24:3086-93. [PubMed: 15044548]

73. Stice E, Burger KS, Yokum S. Relative ability of fat and sugar tastes to activate reward, gustatory, and somatosensory regions. The American journal of clinical nutrition. 2013; 98:1377-84. [PubMed: 24132980]

74. Popkin BM, Nielsen SJ. The sweetening of the world's diet. Obesity Research. 2003; 11:1325-32. [PubMed: 14627752]

75. Leibowitz SF, Dourmashkin JT, Chang GQ, Hill JO, Gayles EC, Fried SK, et al. Acute high-fat diet paradigms link galanin to triglycerides and their transport and metabolism in muscle. Brain research. 2004; 1008:168-78. [PubMed: 15145753]

76. Wang J, Akabayashi A, Yu HJ, Dourmashkin J, Alexander JT, Silva I, et al. Hypothalamic galanin: control by signals of fat metabolism. Brain research. 1998; 804:7-20. [PubMed: 9729239]

77. Parrado C, Diaz-Cabiale Z, Garcia-Coronel M, Agnati L, Covenas R, Fuxe K, et al. Region specific galanin receptor/neuropeptide Y Y1 receptor interactions in the tel-and diencephalon of the rat. Relevance for food consumption. Neuropharmacology. 2007; 52:684-92. [PubMed: 17087983]

78. Schultz W, Apicella P, Ljungberg T. Responses of monkey dopamine neurons to reward and conditioned-stimuli during successive steps of learning a delayed-response task. Journal of Neuroscience. 1993; 13:900-13. [PubMed: 8441015]

79. Berridge KC, Robinson TE. What is the role of dopamine in reward: hedonic impact, reward learning, or incentive salience? Brain Research Reviews. 1998; 28:309-69. [PubMed: 9858756]

80. Koob GF, Le Moal M. Drug addiction, dysregulation of reward, and allostasis. Neuropsychopharmacology. 2001; 24:97-129. [PubMed: 11120394]

81. Epstein LH, Dearing KK, Temple JL, Cavanaugh MD. Food reinforcement and impulsivity in overweight children and their parents. Eating behaviors. 2008; 9:319-27. [PubMed: 18549991]

82. Nederkoorn C, Jansen E, Mulkens S, Jansen A. Impulsivity predicts treatment outcome in obese children. Behaviour research and therapy. 2007; 45:1071-5. [PubMed: 16828053]

83. Stoeckel LE, Murdaugh DL, Cox JE, Cook EW III, Weller RE. Greater impulsivity is associated with decreased brain activation in obese women during a delay discounting task. Brain imaging and behavior. 2013:1-13. [PubMed: 22660945]

84. Kishinevsky FI, Cox JE, Murdaugh DL, Stoeckel LE, Cook EW III, Weller RE. fMRI reactivity on a delay discounting task predicts weight gain in obese women. Appetite. 2012; 58:582-92. [PubMed: 22166676]

85. Batterink L, Yokum S, Stice E. Body mass correlates inversely with inhibitory control in response to food among adolescent girls: an fMRI study. Neuroimage. 2010; 52:1696-703. [PubMed: 20510377]

86. Cornier MA, Salzberg AK, Endly DC, Bessesen DH, Tregellas JR. Sex-based differences in the behavioral and neuronal responses to food. Physiology \& Behavior. 2010; 99:538-43. [PubMed: 20096712] 
87. Del Parigi A, Gautier JF, Chen K, Salbe AD, Ravussin E, Reiman E, et al. Neuroimaging and obesity: mapping the brain responses to hunger and satiation in humans using positron emission tomography. Annals of the New York Academy of Sciences. 2002; 967:389-97. [PubMed: 12079866]

88. Berthoud HR, Zheng H, Shin AC. Food reward in the obese and after weight loss induced by calorie restriction and bariatric surgery. Annals of the New York Academy of Sciences. 2012; 1264:36-48. [PubMed: 22616827]

89. Kenny PJ. Reward Mechanisms in Obesity: New Insights and Future Directions. Neuron. 2011; 69:664-79. [PubMed: 21338878] 


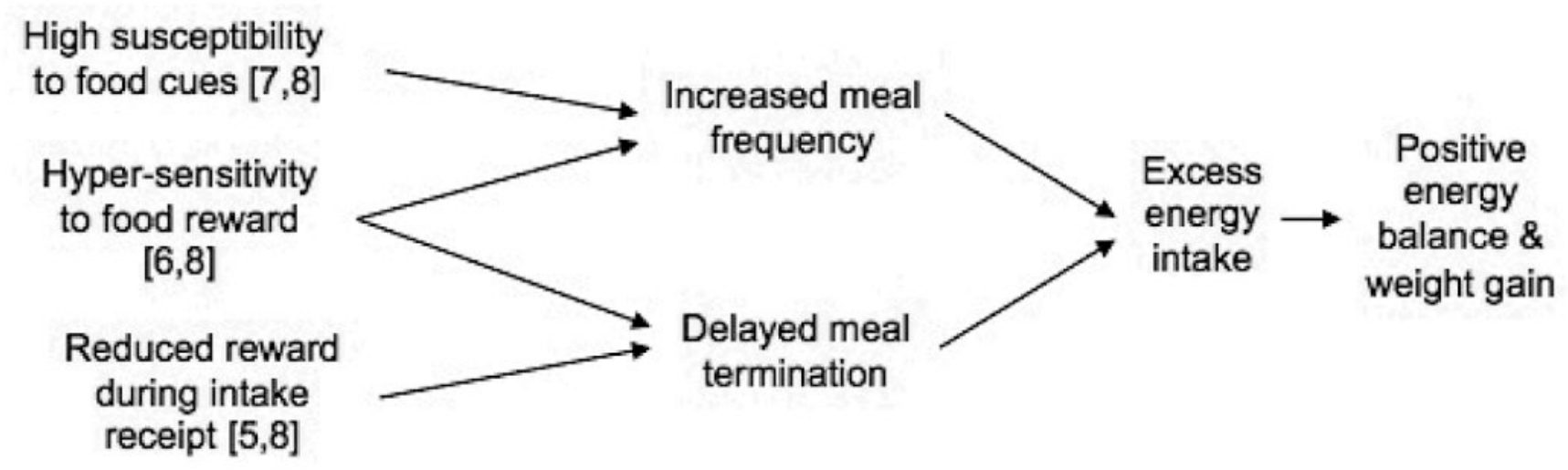

Figure 1.

Possible ingestive behavior mechanisms of reward-based theories of obesity. 
Table 1

Appetitive hormones relation to food intake, obesity, and BOLD response to food images

\begin{tabular}{|c|c|c|c|c|}
\hline Hormone & $\begin{array}{l}\text { Perceived effect on } \\
\text { food intake }\end{array}$ & $\begin{array}{l}\text { Association with } \\
\text { acute food intake }\end{array}$ & $\begin{array}{c}\text { Relation to excess } \\
\text { weight }\end{array}$ & $\begin{array}{l}\text { Effect on BOLD response during } \\
\text { food image exposure }\end{array}$ \\
\hline Leptin & Meal termination & Decreased [39] & $\begin{array}{l}\text { Higher circulating levels; } \\
\text { Leptin resistance[35, 38] }\end{array}$ & $\begin{array}{l}\text { Leptin replacement reduced striatal } \\
\text { and insula activity and increases } \\
\text { prefrontal activity }[40,41]\end{array}$ \\
\hline Peptide YY (PYY) & Meal termination & Decreased [42] & $\begin{array}{l}\text { Lower circulating levels } \\
\text { [42] }\end{array}$ & $\begin{array}{l}\text { Exogenous administration reduced } \\
\text { striatal, insula and OFC activity [47] }\end{array}$ \\
\hline $\begin{array}{c}\text { Glucagon-like peptide } \\
1 \text { (GLP-1) }\end{array}$ & Meal termination & Decreased $[43,44]$ & $\begin{array}{l}\text { Attenuated release to } \\
\text { food intake [43] }\end{array}$ & $\begin{array}{l}\text { Exogenous administration reduced } \\
\text { striatal, insula and OFC activity [47] }\end{array}$ \\
\hline Ghrelin & Meal initiation & Increased $[53,54]$ & $\begin{array}{l}\text { Lower circulating levels; } \\
\text { levels maintain } \\
\text { postprandial }\end{array}$ & $\begin{array}{c}\text { Exogenous administration increased } \\
\text { striatal, amygdala anterior insula and } \\
\text { OFC activity [55] }\end{array}$ \\
\hline Insulin & Meal termination & Decreased [57] & $\begin{array}{l}\text { Higher circulating levels; } \\
\text { Insulin resistance [57] }\end{array}$ & $\begin{array}{l}\text { Intranasal administration reduced } \\
\text { fusiform gyrus hippocampus, } \\
\text { temporal superior and middle frontal } \\
\text { cortices activity [58]. }\end{array}$ \\
\hline
\end{tabular}


Table 2

\section{Relation to food intake and BOLD response to food stimuli}

\begin{tabular}{|c|c|c|}
\hline Food intake measure/study design & Food stimuli during scan & Relation to BOLD response during food image exposure \\
\hline $\begin{array}{l}\text { Ad lib milkshake consumption (post- } \\
\text { scan) }\end{array}$ & $\begin{array}{l}\text { Milkshake receipt }>\text { tasteless solution } \\
\text { receipt }\end{array}$ & $\begin{array}{l}\text { Response in midbrain and medial OFC was positively } \\
\text { predicted subsequent ad lib milkshake intake [64] }\end{array}$ \\
\hline Ad lib snack consumption (post-scan) & $\begin{array}{l}\text { Food images }>\text { images of non-food } \\
\text { household items }\end{array}$ & $\begin{array}{l}\text { Response in ventral striatum was positively related to ad lib } \\
\text { snack intake [65] }\end{array}$ \\
\hline $\begin{array}{l}\text { Doubly-labeled water estimates of } \\
\text { two-week energy intake }\end{array}$ & $\begin{array}{l}\text { Cues predicting milkshake receipt }> \\
\text { cues predicting tasteless solution } \\
\text { receipt }\end{array}$ & $\begin{array}{l}\text { Response in the visual and anterior cingulate cortices, } \\
\text { precuneus, primary gustatory cortex (frontal operculum) } \\
\text { and striatum was positively related to energy intake [66] }\end{array}$ \\
\hline Ad lib meal consumption (post-scan) & $\begin{array}{l}\text { Appetizing food images }>\text { non-food } \\
\text { objects }\end{array}$ & $\begin{array}{l}\text { Ad libitum meal intake was related to decreased dorsolateral } \\
\text { prefrontal cortex response }[86]\end{array}$ \\
\hline $\begin{array}{l}\text { Comparison of habitual soft drink } \\
\text { consumers vs. BMI-matched controls }\end{array}$ & $\begin{array}{l}\text { Soft drink brand advertisements }>\text { non- } \\
\text { food advertisements }\end{array}$ & $\begin{array}{l}\text { Response in the precuneus was greater in habitual soft drink } \\
\text { consumers [67] }\end{array}$ \\
\hline $\begin{array}{l}\text { Self-reported artificial sweetener use } \\
\text { in habitual diet soft drink consumers }\end{array}$ & $\begin{array}{l}\text { Saccharin solution receipt }>\text { tasteless } \\
\text { solution receipt }\end{array}$ & $\begin{array}{l}\text { Artificial sweetener use was related to decreased striatal } \\
\text { response [68] }\end{array}$ \\
\hline Self-reported artificial sweetener use & $\begin{array}{l}\text { Sucrose solution receipt }>\text { tasteless } \\
\text { solution receipt }\end{array}$ & $\begin{array}{l}\text { Artificial sweetener use was related decreased response in } \\
\text { the insula and amygdala [69] }\end{array}$ \\
\hline $\begin{array}{l}\text { Self-reported intake of ice cream and } \\
\text { frozen dessert }\end{array}$ & $\begin{array}{c}\text { Milkshake receipt }>\text { tasteless solution } \\
\text { receipt }\end{array}$ & $\begin{array}{l}\text { Frequency of ice cream intake was related to decreased } \\
\text { ventral striatum, insula and ventromedial prefrontal cortex } \\
{[70]}\end{array}$ \\
\hline
\end{tabular}

